
Multidisciplinary
SCIENTIFIC JOURNAL

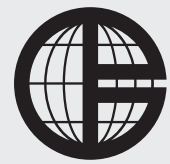
Multidisciplinarni
OF MARITIME RESEARCH
University of Rijeka
znanstveni časopis
POMORSTVO
FACULTY OF MARITIME STUDIES

\title{
Methodological approach on optimizing the speed of navigation to reduce fuel consumption and increase energy efficiency of the cruising ship
}

\author{
Radoslav Radonja, Vladimir Pelić, Davor Pavić, Darko Glujić \\ University of Rijeka, Faculty of Maritime Studies, Studentska 2, 51000 Rijeka, Croatia, e-mail: radonja@pfri.hr
}

\section{ABSTRACT}

Modern large cruise ships have great energy needs for different technological processes on board. The energy needs depend on the operating conditions and the required speed of the ship, and the high energy requirements usually mean high fuel costs. With the enforcement of international regulations aimed at reducing environmental pollution, various measures and procedures have been proposed to increase the energy efficiency of ships. This paper outlines method that can be applied to ships without installing new or modification of existing systems and will require somewhat increased attention of chief engineer during voyage and his close cooperation with the captain. Traditionally, the required speed of the ship will be determined by the length of the fairway divided by the time that is available for travel. Analyzing originally collected data from the cruising ship it was concluded that by optimizing the speed of navigation according to the requirements of the route it is possible to achieve significant fuel savings, reduce travel costs, increase energy efficiency and reduce environmentally harmful emissions of the ship.
\end{abstract}

\section{ARTICLE INFO}

Preliminary communication

Received 10 May 2019

Accepted 26 November 2019

Key words:

Cruising ship

Ship energy efficiency

Cruising speed optimization

\section{Introduction}

Amendments to the MARPOL 73/78 Convention and its Annex 6 [1] (enforced from 1.1.2013) for new and existing ships impose new requirements with the aim of reducing the emissions of harmful gases from vessels energy systems and increasing the energy efficiency. For new ships the International Energy Efficiency Certificate (IEEC), the Ship Energy Efficiency Management Plan (SEEMP) and the Energy Efficiency Design Index (EEDI) are required, except the last one is not obligatory for existing ships.

The Ship Energy Efficiency Management Plan contains a set of measures aimed at establishing economically viable mechanisms to improve the ship's energy efficiency. The plan also enables shipping companies to manage the energy efficiency of ships and entire fleet through a non-mandatory Energy Efficiency Operational Indicator (EEOI).

Energy Efficiency Index (EEDI) is a technical measure aimed at promoting energy-efficient and environmentallyfriendly plants and equipment. EEDI for different types of ships requires the lowest possible energy consumption per 'tonne mille' but it is not required for existing engines.
Currently, relevant publications that address this issue include over 50 processes that can increase energy efficiency of ships [2]. Among these processes are most commonly mentioned: voyage optimization, energy consumption management, hull propulsion and plant maintenance, structural alteration (modification) or the use of alternative fuels [3].

This paper shows that significant savings in fuel economy can only be achieved by optimizing the speed of navigation on a particular section of the route. The distance between the port of departure and the port of arrival is to be divided into two stages and the required speed, time of navigation, distance traveled and fuel consumption will be calculated for each stage. Sections must be selected so that the sum of the fuel consumption of each stage is lower than the fuel consumption of the ship, if the ship sailed from the port of departure to the port of arrival at constant speed. To optimize the fairway, ship speed and required power relationship diagram can be used ${ }^{1}$.

\footnotetext{
1 The diagram is based on experimental knowledge and is valid for 'Voyager' class of ships.
} 


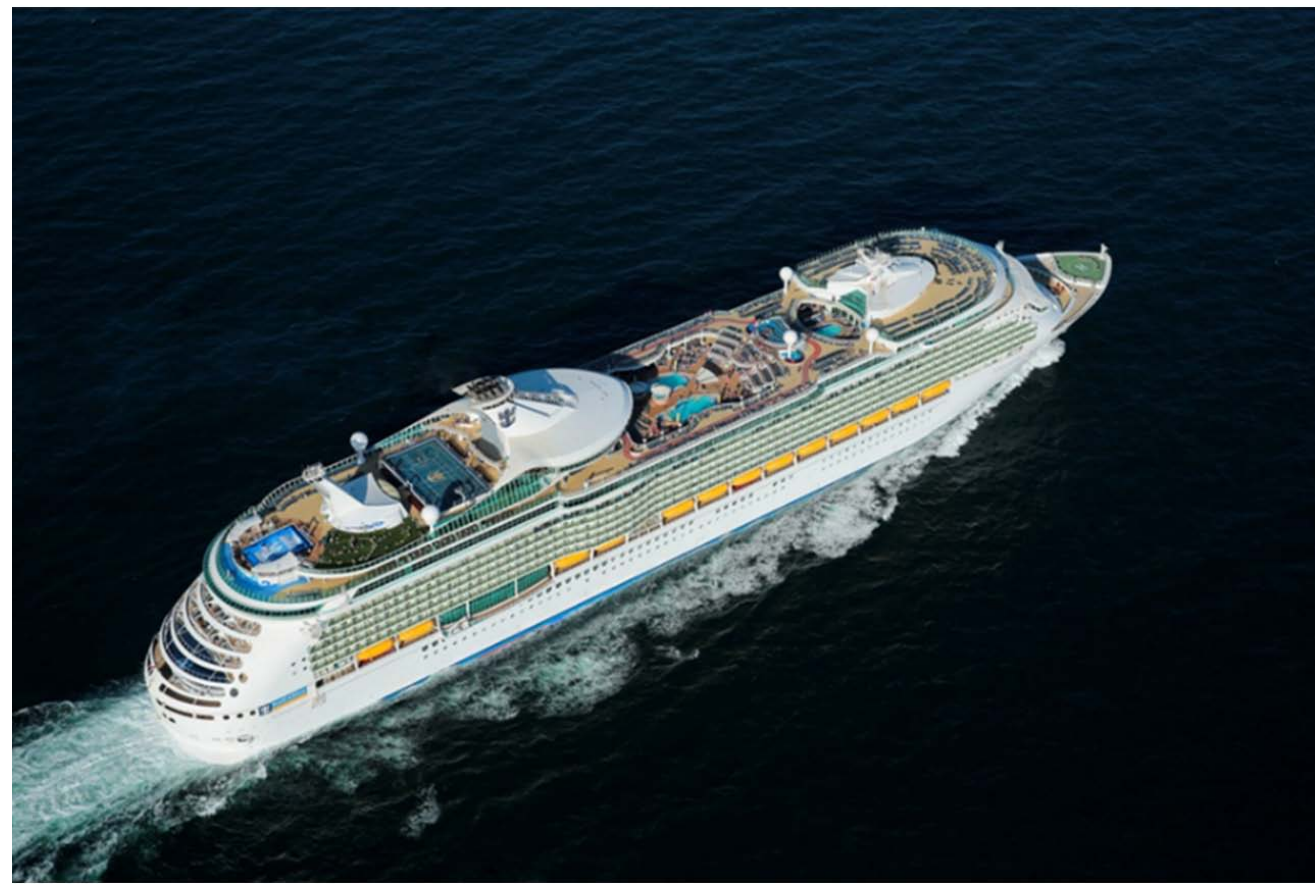

Figure 1 The "Voyager" class ship [4]

\section{General characteristic of the ship}

The ship was built in the "Voyager" class in the shipyard "Kvaerner Masa" in the Finnish city of Turku (Figure 1). With a length overall of $311.1 \mathrm{~m}$, a beam of $38.6 \mathrm{~m}$ at the waterline, draft of $8.6 \mathrm{~m}$ and $139,570 \mathrm{BT}$ today is among the largest passenger ships in the world.

The concept of a "fully integrated electrical system" was applied to the ship. The six diesel generators connected to the main distribution board produce high-voltage electricity that is being distributed to consumers: 11 $\mathrm{kV}$ for propulsion engines, bow and stern thrusters, and through $11 \mathrm{kV} / 440 \mathrm{~V}$ transformers for power supply of engine room and hoteling.

The ship propulsion system includes propulsion transformers, frequency inverters and propulsion electric motors. The propulsion system is connected to a common electric power station with constant voltage and frequency, and revolution speed of propulsion electric motor is controlled by a frequency converter and by changing the "ignition angle" of the thyristor. Changing the direction of rotation of the propeller is not recommended unless extreme urgency. It is normal to change the ship direction by rotation of azipods (AZIPOD - brand name for electric podded azimuth thruster) for $180^{\circ}$. During the maneuvering of the ship, the azipods can freely rotate in both directions "Ahead" or "Astern", however the torque in "Astern" run is limited in accordance with propeller characteristics.

The automation system onboard is responsible for the generation and distribution of electricity, automatic startup of an additional diesel generator in the event of an increase of the load on the ship network, as well as the stopping of the additional generator when the load falls below the set value. The power and number of diesel generators that run synchronously are such that with 4 diesel generators working at $85 \%$ load, they cover all the needs of the ship and ensure maximum speed even in tropical areas. In other words, diesel engines are set so that at loads between 80 and $85 \%$ they realize the lowest specific fuel consumption.

\section{Methodological approach}

Typically, the required speed of the ship will be determined by the division of the length of the fairway and the time that is available.

For example, if the ship is scheduled to sail from disembarkation point of the pilot at the port of departure at 17:00 and to arrive at the pilot's embarkation point at the port of arrival at 07:00, it means 10 hours are available for voyage, not counting time spent on maneuvering. The distance between the disembarkation point and the pilot embarkation point is $180 \mathrm{NM}$, so the required speed will be 18 knots. The vessel will sail all the time at an unaltered speed, from the pilot disembarkation point at the port of departure to the point of embarkation of the pilot at the port of arrival. In that case, the energy consumption will be equal to product of the power required to sail the ship at a speed of 18 knots and travel time.

For optimizing purposes, the route is to be divided into several stages (at least two), in which the ship sails at different speeds, and achieves different fuel consumption. Optimization must be carried out so that the total fuel consumption at different stages is lower than the fuel consumption of cruising at constant speed. 

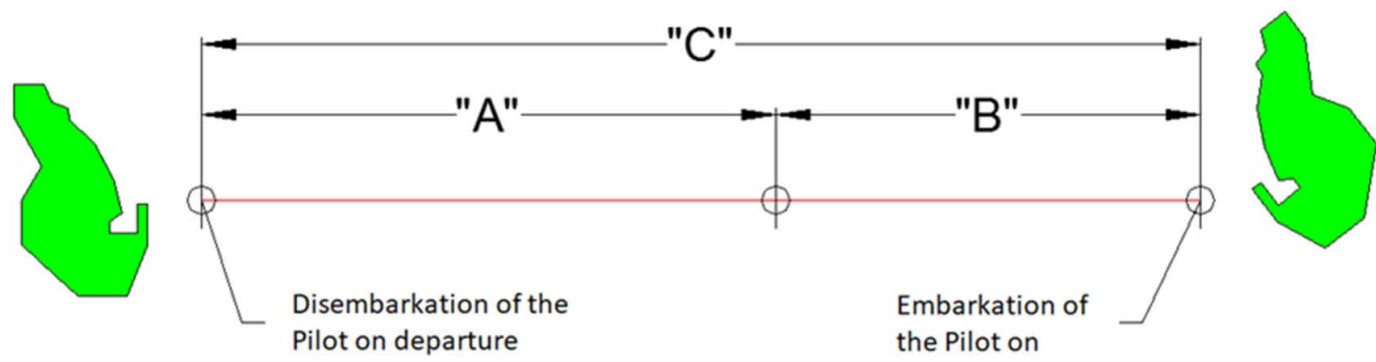

Figure 2 Sailing stages

Source: Authors

The condition that must be satisfied is:

$$
X_{\mathrm{C}}>X_{1}+X_{2}+X_{3}+\ldots+X_{\mathrm{n}}
$$

where:

$X_{\mathrm{C}}$ - fuel consumption of cruising at constant speed

$X_{\mathrm{n}}$ - fuel consumption on different stages (variable speeds).

The distance between the ports can be sailed in two ways; at constant cruising speed at all times of the voyage, or with variable speeds of propulsion engines, i.e. with varying speeds at different stages of the same voyage. Sailing at constant speed is marked with the letter " $\mathrm{C}$ ", and the stages in which the ship sails with variable speeds are marked with letters "A" and "B".
In our example (Figure 2), the condition is:

$$
C=A+B
$$

The diagram (Figure 3) used for calculation is based on real observation and recordings of the consumed power of engines at the different required speeds of the ship [5], [6].

The values were obtained in calm sea condition, windless, with fouling free hull and clean propeller blades.

As it can be seen, the relationship between ship speed and propulsion power is not always the same. In this paper use the fact that wave resistance is not always proportional to the ship speed. The total hull resistance of the ship consists of these main components: viscous resistance, wave resistance and air resistance (Figure 4).

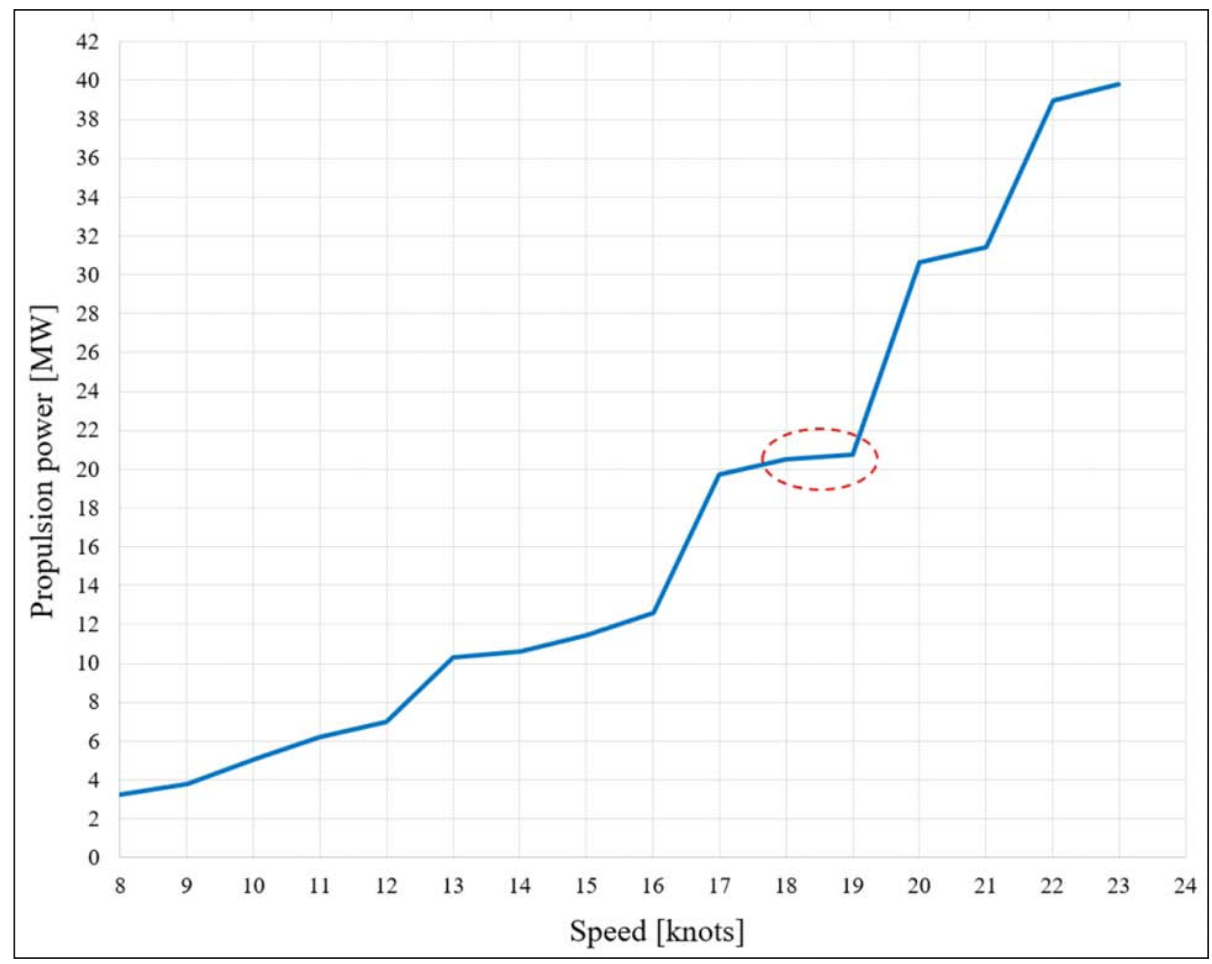

Figure 3 Relationship between ship speed and power required 


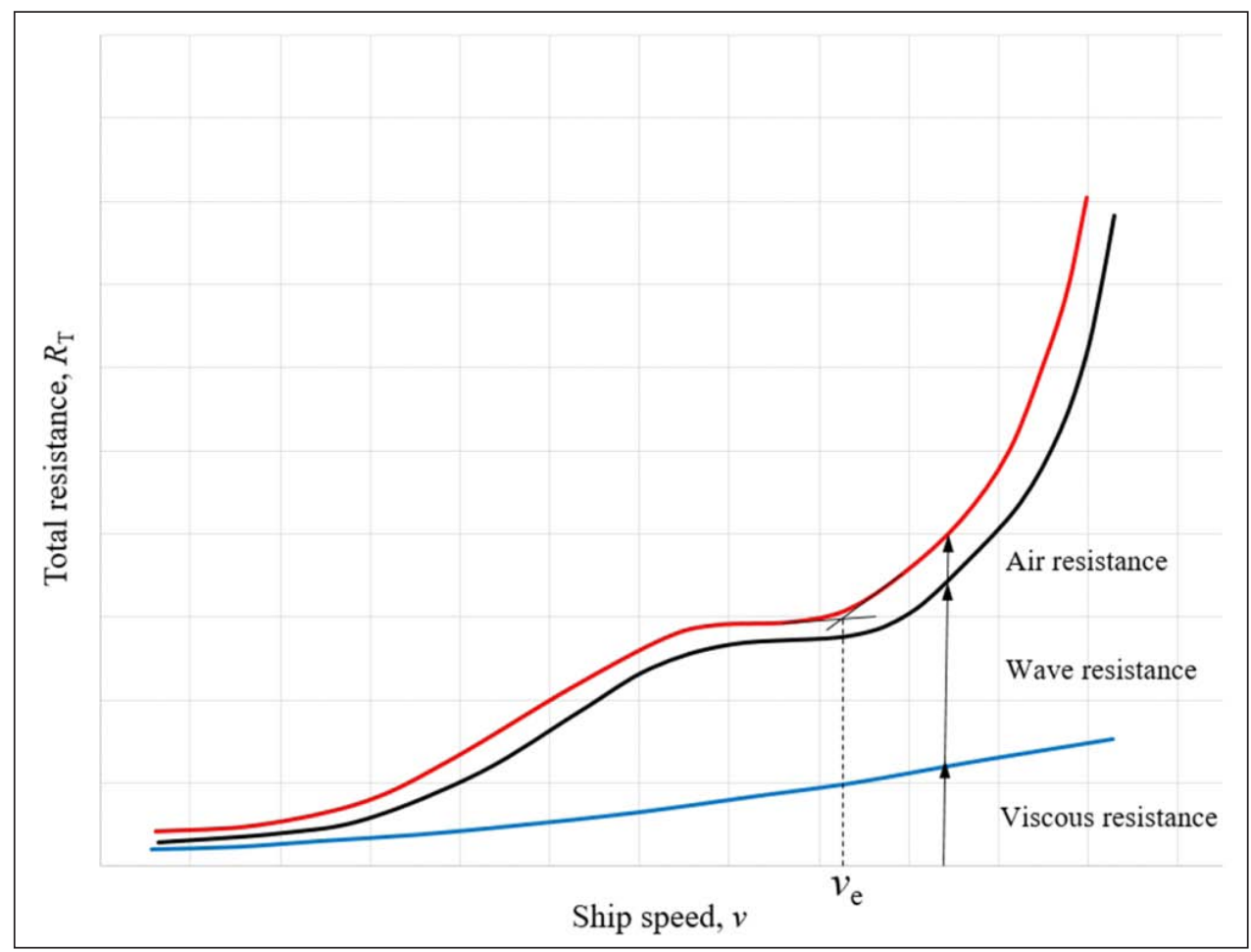

Figure 4 Components of ship Hull Resistance, [7], [8]

Equation for total ship hull resistance is:

$$
R_{\mathrm{T}}=R_{\mathrm{V}}+R_{\mathrm{W}}+R_{\mathrm{A}}
$$

where:

$R_{\mathrm{T}}$ - total hull resistance,

$R_{\mathrm{V}}$ - viscous resistance,

$R_{\mathrm{w}}$ - wave making resistance,

$R_{\mathrm{A}}-$ air resistance caused by ship moving through calm air.

In order to compare model test data to full-scale ship data, naval architects use dimensionless coefficients. According to the dimensional analysis previous equation for total hull resistance in terms of dimensionless coefficients is:

$$
C_{\mathrm{T}}=C_{\mathrm{V}}+C_{\mathrm{w}}
$$

where:

$C_{\mathrm{T}}$ - coefficient total hull resistance,

$C_{\mathrm{V}}$ - coefficient viscous resistance,

$C_{\mathrm{w}}$ - coefficient wave making resistance.

Note: Because most test models do not have superstructures air resistance is not represented in dimensionless form.

Dimensionless form of ship speed - length ratio called the "Froude number", $F_{n}$.

$$
F_{\mathrm{n}}=v /(g \cdot L)^{0,5}
$$

where:

$$
\begin{aligned}
& v \text { - ship speed [m/s], } \\
& L \text { - length on the waterline of ship or model, }[\mathrm{m}] \\
& g \text { - acceleration of gravity }\left[\mathrm{m} / \mathrm{s}^{2}\right] .
\end{aligned}
$$

In Figure 4 total resistance is presented with red line, and $v_{\mathrm{e}}$ is economical speed of ship. If ship sails at a slightly higher speed, the propulsion power and fuel consumption will rise significantly, because power needed for ship propulsion is proportional to total resistance. It is clear from the same diagram, that at low speeds, viscous resistance has the greatest impact, while at higher speeds the proportion of wave resistance is significantly increased.

Experimental explorations on ships models confirmed theoretical considerations on alternating relative increase and decrease of wave resistance when increasing ship speed. This phenomenon is due to the interaction of the bow and stern waves system. The existence of oscillating components (valleys and hills) (Fig. 5) of the ship's resistance, according to the $P$ - theory, was confirmed by the data obtained experimentally at different speeds of the ship model. [7], [8]

Changing the speed of the ship causes a change in the position of the bow wave relative to the stern waves system. In this interaction of wave systems with the increase in wave height results, increase of resistance, and the case of reduction of wave height, there is a relative decrease of wave resistance. [7], [8]

From the diagram in Figure 3 it can be seen, for example, that increasing the speed from 16 to 17 knots requires 


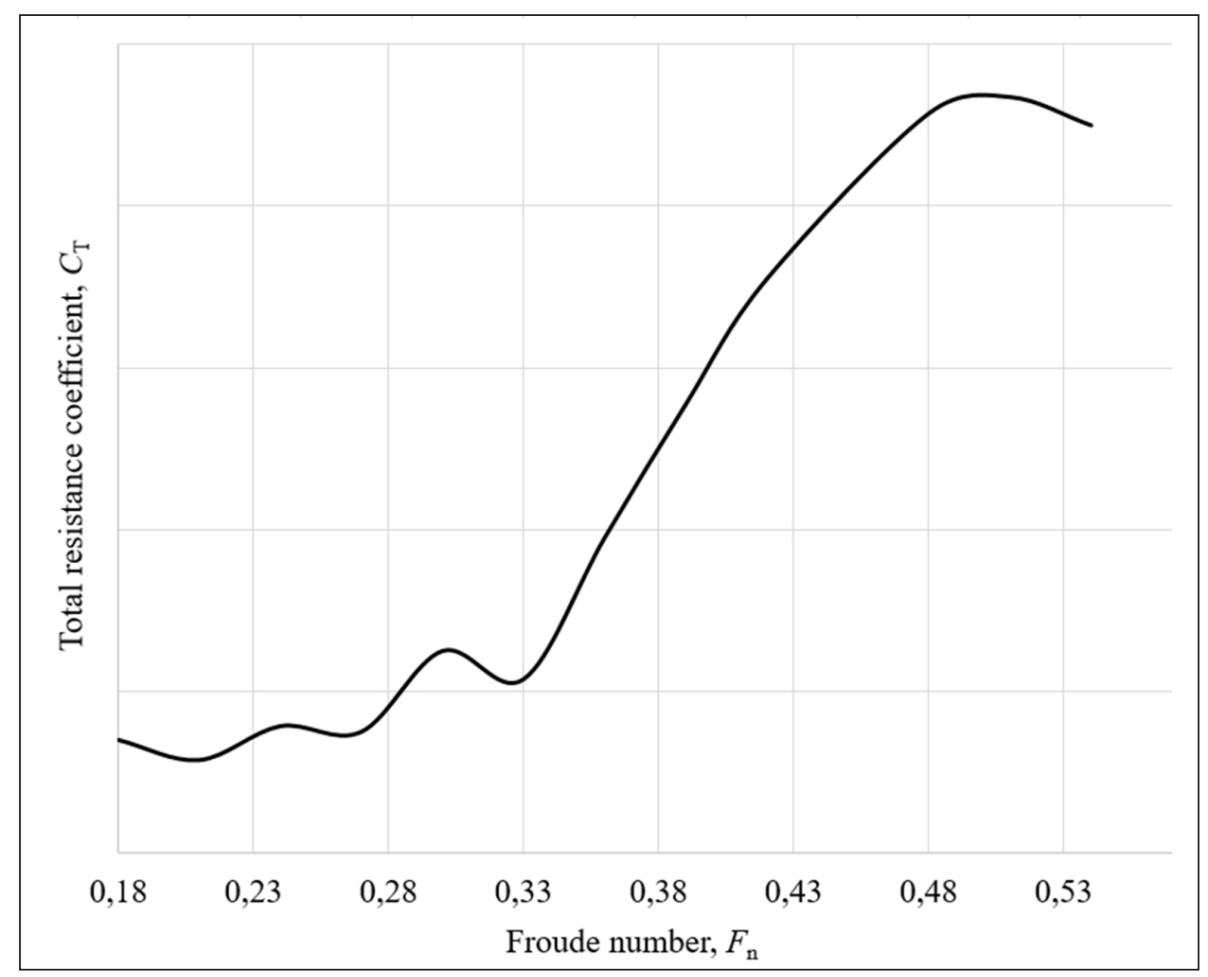

Figure 5 Total resistance coefficient vs. Froude number, [7]

a significantly greater propulsion power than it is the case with increasing the speed of 18 to 19 knots. The method for reducing the fuel consumption presented in this paper is based on this.

\section{Optimization of the speed of navigation}

The ship navigation on seven-day cruises from $\mathrm{Ft}$. Lauderdale FL, USA. The round trip includes the following ports (Figure 6):
1. Ft. Lauderdale - USA,

2. Labadie - Haiti,

3. San Juan - Puerto Rico (USA),

4. Basseterre - St. Kitts and Nevis,

5. Philipsburg - St. Maarten,

6. Ft. Lauderdale-USA.

Average fuel consumption on round trips is $928.00 \mathrm{t}$ per week or 3,712.00 $\mathrm{t}$ per month (4 trips) or $44,544.00 \mathrm{t}$ per year (48 trips).

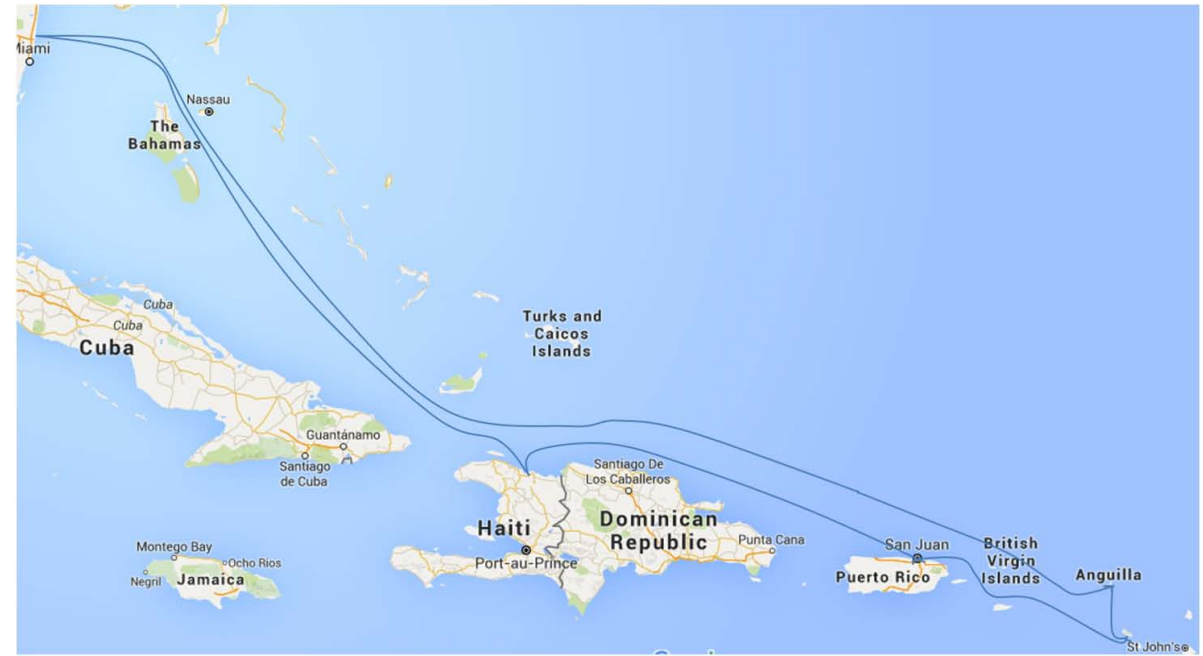

Figure 6 Sailing area on a round trip 
We only consider sailing from the moment of the pilot's disembarking at the port of departure to the pilot's boarding at the arrival point. With a proper selection of stage " $\mathrm{A}$ " and "B" it is possible to achieve better fuel economy in relation to sailing at constant speed on the same section and equal weather conditions.

\subsection{Stage 1: Ft. Lauderdale - Labadie}

When sailing with constant speed the ship will cross the distance from Ft. Lauderdale to Labadie which is $624 \mathrm{NM}$ at a constant speed of 17.21 knots for 36.25 hours. The required power is $19.90 \mathrm{MW}$, the energy used for ship propulsion is $721.38 \mathrm{MWh}$ and the fuel consumption is $219.41 \mathrm{t}$.
If the trip is divided into two stages:

Stage A - distance $481 \mathrm{NM}$, sailing time 26 hours at a speed of 18.5 knots. The required power is $20.61 \mathrm{MW}$, the energy used for ship propulsion is $535.86 \mathrm{MWh}$ and the fuel consumption is $154.67 \mathrm{t}$.

Stage B - distance 143 NM, sailing time 10.25 hours, at speed of 13.95 knots. The required power is $10.58 \mathrm{MW}$, the energy used for ship propulsion is $108.45 \mathrm{MWh}$ and the fuel consumption is $40.72 \mathrm{t}$.

Sailing at 18.5 knots for 26 hours and at 13.95 knots for 10.25 hours, the ship consumed $24.02 \mathrm{t}$ of fuel less than with constant cruising speed of 17.21 knots for 36.25 hours. (Tab. 1, Fig. 7)

Table 1 Optimization - stage 1: Ft. Lauderdale - Labadie

\begin{tabular}{|c|c|c|c|c|}
\hline & C & $\mathbf{A}$ & B & $A+B$ \\
\hline Distance & $624 \mathrm{NM}$ & $481 \mathrm{NM}$ & $143 \mathrm{NM}$ & $624 \mathrm{NM}$ \\
\hline Time & $36,25 \mathrm{~h}$ & $26,00 \mathrm{~h}$ & $10,25 \mathrm{~h}$ & $36,25 \mathrm{~h}$ \\
\hline Speed & $17,21 \mathrm{NM} / \mathrm{h}$ & $18,50 \mathrm{NM} / \mathrm{h}$ & $13,95 \mathrm{NM} / \mathrm{h}$ & \\
\hline Propulsion power & $19,90 \mathrm{MW}$ & 20,61 MW & 10,58 MW & \\
\hline Electric power & 8,70 MW & 7,90 MW & 8,30 MW & \\
\hline Total electric power & 28,60 MW & 28,51 MW & 18,88 MW & \\
\hline SFOC & $0,212 \mathrm{~kg} / \mathrm{kWh}$ & $0,209 \mathrm{~kg} / \mathrm{kWh}$ & $0,210 \mathrm{~kg} / \mathrm{kWh}$ & \\
\hline
\end{tabular}

"Electric power" - average electric power consumption of all electric costumers; SFOC - specific fuel oil consumption

Source: Authors

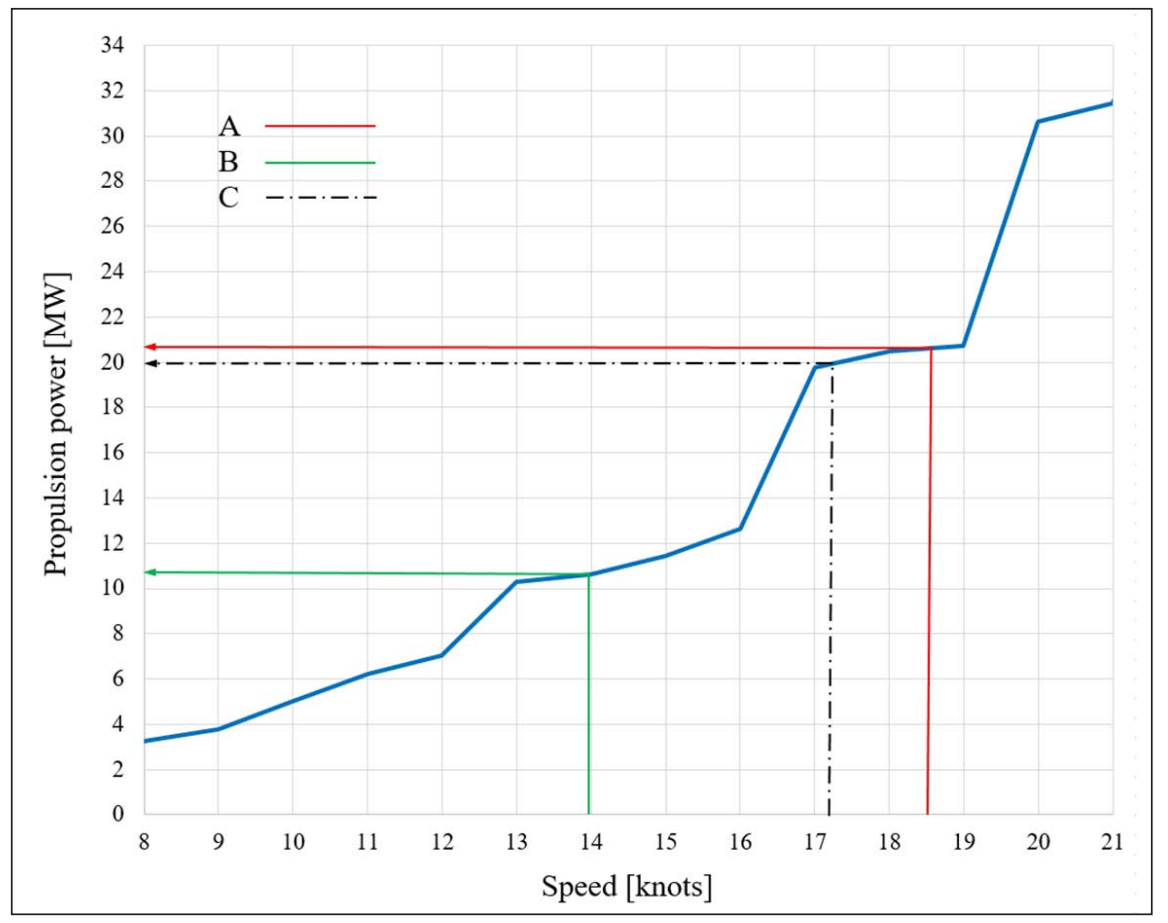

Figure 7 Optimization - stage 1: Ft. Lauderdale - Labadie 


\subsection{Stage 2: Labadie - San Juan}

Due to relatively short navigation and the high speed required, optimization cannot achieve savings.

\subsection{Stage 3: San Juan - Basseterre}

At constant speed of 18.53 knots, the ship will cross the distance from San Juan to Basseterre, which amounts to $229 \mathrm{NM}$ for 12.35 hours. The required power is 20.61 MW, the energy used for ship propulsion is $254.53 \mathrm{MWh}$, and the fuel consumption is $73.47 \mathrm{t}$.
If the trip is divided into two stages:

Stage A - distance 190 NM, sailing time 10 hours at a speed of 19 knots. The required power is $20.73 \mathrm{MW}$, the energy used for ship propulsion is $207 \mathrm{MWh}$ and the fuel consumption is $59.75 \mathrm{t}$.

Stage B - distance 39 NM, sailing time 2.35 hours, at speed of 16.55 knots. The required power is $16.54 \mathrm{MW}$, the energy used for ship propulsion is $38.87 \mathrm{MWh}$ and the fuel consumption is $11.85 \mathrm{t}$.

Sailing at 19 knots for 10 hours and at 16.55 knots for 2.35 hours, the ship consumed $1.87 \mathrm{t}$ of fuel less than with constant cruising speed of 18.53 knots for 12.35 hours. (Tab. 2, Fig. 8)

Table 2 Optimization - stage 3: San Juan - Basseterre

\begin{tabular}{|c|c|c|c|c|}
\hline & C & A & B & $A+B$ \\
\hline Distance & $229 \mathrm{NM}$ & $190 \mathrm{NM}$ & $39 \mathrm{NM}$ & $229 \mathrm{NM}$ \\
\hline Time & $12,35 \mathrm{~h}$ & $10,00 \mathrm{~h}$ & $2,35 \mathrm{~h}$ & $12,35 \mathrm{~h}$ \\
\hline Propulsion power & 20,61 MW & 20,73 MW & 16,54 MW & \\
\hline Electric power & 7,80 MW & 7,80 MW & 7,70 MW & \\
\hline Total electric power & 28,41 MW & $28,53 \mathrm{MW}$ & $24,24 \mathrm{MW}$ & \\
\hline SFOC & $0,209 \mathrm{~kg} / \mathrm{kWh}$ & $0,209 \mathrm{~kg} / \mathrm{kWh}$ & $0,208 \mathrm{~kg} / \mathrm{kWh}$ & \\
\hline
\end{tabular}

"Electric power" - average electric power consumption of all electric costumers; SFOC - specific fuel oil consumption

Source: Authors

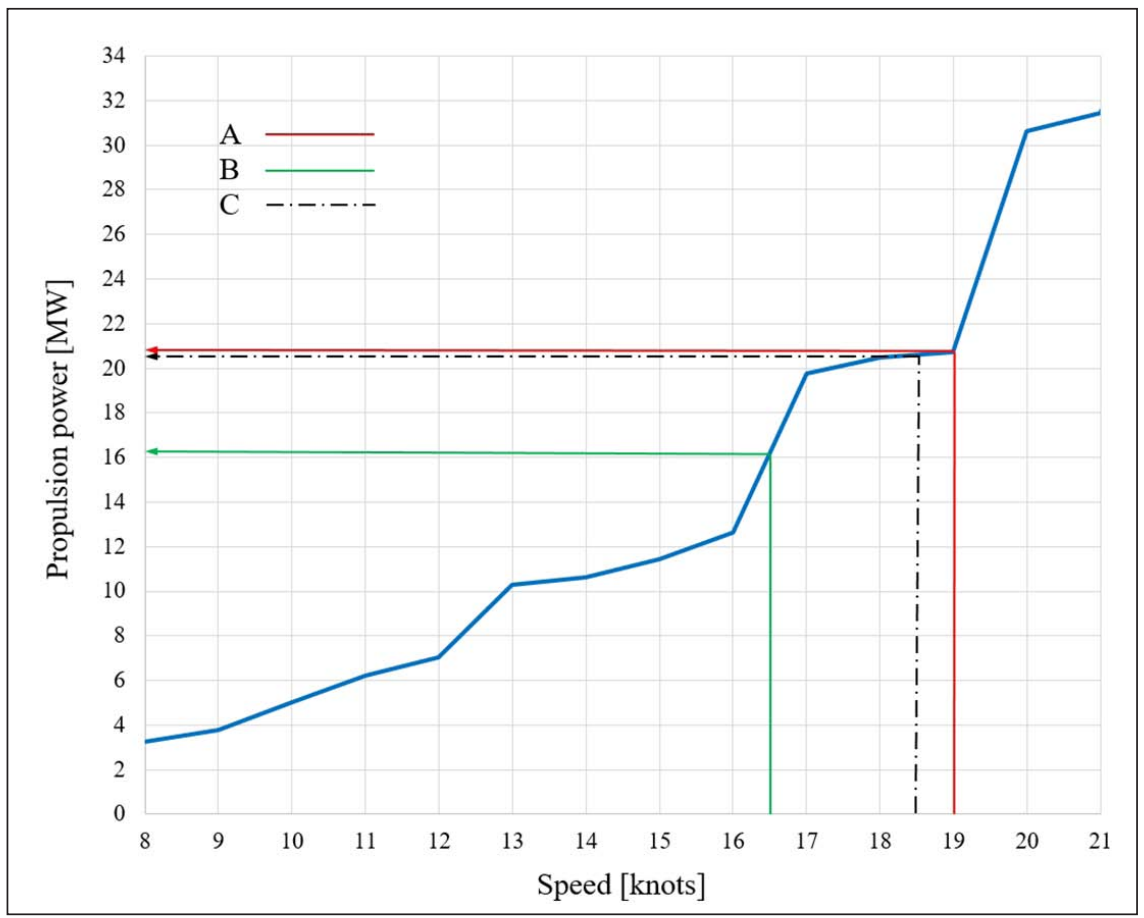

Figure 8 Optimization - stage 3: San Juan - Basseterre 


\subsection{Stage 4: Basseterre - Philipsburg}

Due to relatively short navigation and the low speed required, optimization cannot achieve savings.

\subsection{Stage 5: Philipsburg - Ft. Lauderdale}

At constant speed of 18.28 knots, the ship will cross the distance from Philipsburg to Ft. Lauderdale, which amounts to $1083 \mathrm{NM}$ for 59.25 hours. The required power is $20.55 \mathrm{MW}$ the energy used for ship propulsion is 1217.59 MWh, and the fuel consumption is $356.16 \mathrm{t}$.
If the trip is divided into two stages:

Stage A - distance 925 NM, sailing time 50 hours at a speed of 18.5 knots. The required power is $20.61 \mathrm{MW}$, the energy used for ship propulsion is $1030.50 \mathrm{MWh}$ and the fuel consumption is $297.44 \mathrm{t}$.

Stage B - distance 158 NM, sailing time 9.25 hours, at speed of 17.08 knots. The required power is $19.80 \mathrm{MW}$, the energy used for ship propulsion is $183,15 \mathrm{MWh}$ and the fuel consumption is $53.68 \mathrm{t}$.

Sailing at 18.5 knots for 50 hours and at 17.08 knots for 9.25 hours, the ship consumed $5.04 \mathrm{t}$ of fuel less than with constant cruising speed of 18.28 knots for 59.25 hours. (Tab. 3, Fig. 9)

Table 3 Optimization - stage 5: Philipsburg - Ft. Lauderdale

\begin{tabular}{|c|c|c|c|c|}
\hline & C & $\mathbf{A}$ & B & $A+B$ \\
\hline Distance & $1083 \mathrm{NM}$ & $925 \mathrm{NM}$ & $158 \mathrm{NM}$ & $1083 \mathrm{NM}$ \\
\hline Time & $59,25 \mathrm{~h}$ & $50,00 \mathrm{~h}$ & $9,25 \mathrm{~h}$ & $59,25 \mathrm{~h}$ \\
\hline Propulsion power & 20,55 MW & 20,61 MW & 19,80 MW & \\
\hline Electric power & 7,95 MW & 7,80 MW & 7,80 MW & \\
\hline Total electric power & 28,50 MW & 28,41 MW & $27,60 \mathrm{MW}$ & \\
\hline SFOC & $0,211 \mathrm{~kg} / \mathrm{kWh}$ & $0,209 \mathrm{~kg} / \mathrm{kWh}$ & $0,210 \mathrm{~kg} / \mathrm{kWh}$ & \\
\hline
\end{tabular}

"Electric power" - average electric power consumption of all electric costumers; SFOC - specific fuel oil consumption

Source: Authors

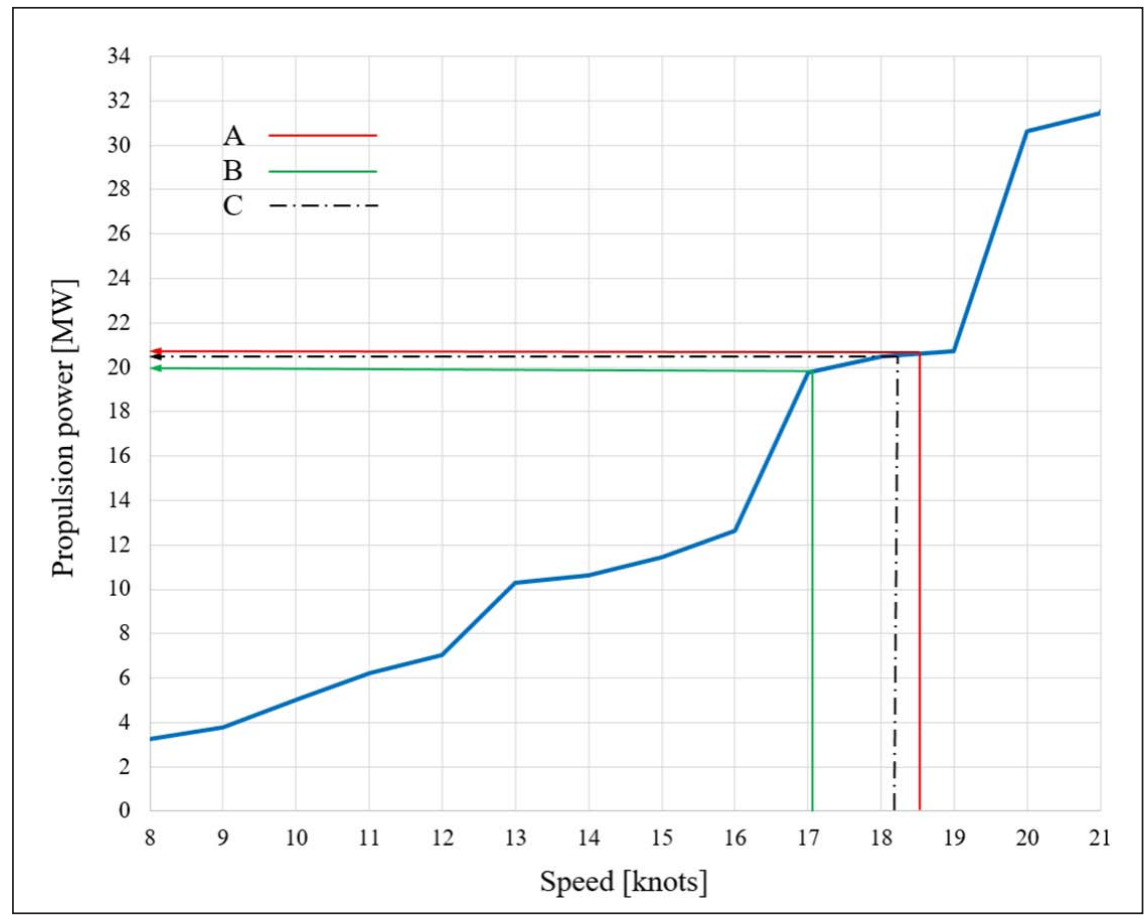

Figure 9 Optimization - stage 5: Philipsburg - Ft. Lauderdale 
Table 4 Optimization of the speed of navigation - resume

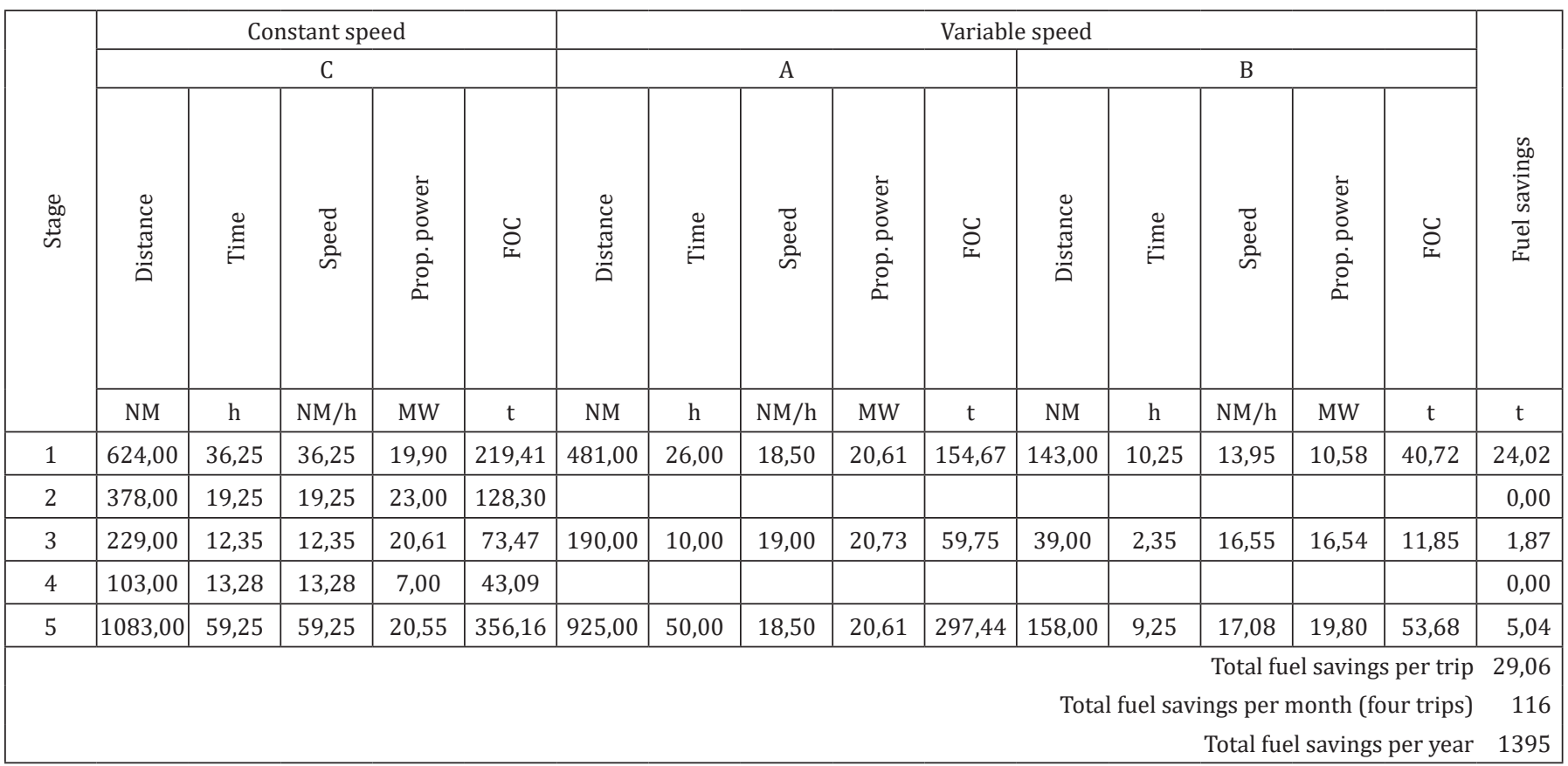

FOC - fuel oil consumption

Source: Authors

\section{Discussion}

Thanks to the optimization of navigation speed, total fuel savings for one round trip would amount to $29.06 \mathrm{t}$, 116.20 t per month ( 4 trips), or 1395.00 t per year (Table 4).

This paper shows that fuel savings can be achieved by optimizing cruising speeds during travel but chief engineer on board has to prepare experimental diagram of relationship between the speed of the ship and power consumption (which are not always proportional). The distance between the port of departure and the port of arrival is to be divided at least into two stages and calculation for each stage must be made: the required speed, time of navigation, distance traveled and fuel consumption. The footpaths must be selected so that the sum of the fuel consumption at each stage is lower than the fuel consumption if the ship is sailing from the port of departure to the port of arrival at constant speed. It is to be noted that in this paper the stages were divided in two segments with variable speed for the purpose of presenting the method, but it is not limited for alternations. The method is mostly applicable for the ship sailing on the same route.

\section{Conclusion}

This paper outlines method that can be applied to cruising ships without installing new or modifications of existing systems aiming to achieve the goal of energy efficiency, fuel savings and reducing environmentally harmful emissions.
Traditionally, the captain will determine the required cruise speed for a particular voyage so that the length of the trip is divided with the time available. The vessel will sail all the time at an unaltered calculated speed, from the pilot disembarkation point at the port of departure to the point of embarkation of the pilot at the port of arrival. In that case, the energy consumption will be equal to product of the power required for ship to sail at the calculated speed and time of travel. However, this paper shows that fuel savings can be achieved by optimizing cruising speeds during travel.

Finally, the method presented in this paper relates to 'Voyager' class of cruise ships and results of this research are implemented as a common practice on board. The principle is applicable in general, although in some cases it won't be possible to achieve such savings. However, to decide when it can be achieved, a close cooperation has to be established between the captain and the chief engineer onboard from the very beginning of planning the voyage and throughout the entire trip.

Further research will be focused on waste heat recovery systems on the same type of the ship to achieve better energy efficiency and fuel savings as well.

\section{References}

[1] http://www.imo.org/en/KnowledgeCentre/IndexofIMOResolutions/Marine-Environment-Protection-Committee-(MEPC)/ Documents/MEPC.203(62).pdf, last acc. 15/05/2019.

[2] OCIMF. (2011). GHG Emissions- Mitigating Measures for Oil Tankers. London: OCIMF Oil Companies International Maine Forum, available at: https://www.ocimf.org/media/8922/ 
GHG\%20Emission-Mitigating\%20Measures\%20for\%20 0il\%20Tankers\%20Part\%20A\%20Review\%20of\%20Reduction\%20Potential\%20FINAL.pdf, last acc. 15/05/2019.

[3] Energy saving - course, ABB, Helsinki 29/08/2013 - personal records.

[4] https://www.cruise118.com/advice/popular-cruise-ships2016/navigator-of-the-seas-aerial/, last acc. 15/05/2019.
[5] Technical documentation of the 'Voyager' class cruising ship

[6] Technical personal records from the 'Voyager' class cruising ship.

[7] Radan, D., Uvod u hidrodinamiku broda, Sveučilište u Dubrovniku, Dubrovnik, 2004.

[8] Vučinić, A., Hidrodinamika plovnih objekata, Sveučilište u Rijeci, Rijeka, 1997. 